Article

\title{
Critical Factors to Achieve Dockless Bike-Sharing Sustainability in China: A Stakeholder-Oriented Network Perspective
}

\author{
Jian-gang Shi ${ }^{1}$, Hongyun $S i^{1}{ }^{1} * \mathbb{C}$, Guangdong $\mathrm{Wu}^{2}{ }^{2}$, , Yangyue $\mathrm{Su}^{1}$ and Jing Lan ${ }^{1}$ \\ 1 School of Economics and Management, Tongji University, Shanghai 200092, China; \\ sjg126com@126.com (J.S.); 1710260@tongji.edu.cn (Y.S.); 1410329@tongji.edu.cn (J.L.) \\ 2 School of Tourism and Urban Management, Jiangxi University of Finance \& Economics, \\ Nanchang 330013, China; gd198410@163.com \\ * Correspondence: sihongyun@tongji.edu.cn
}

Received: 15 May 2018; Accepted: 17 June 2018; Published: 20 June 2018

check for updates

\begin{abstract}
In China, dockless bike-sharing programs (DBSPs) play a significant role in promoting the goals of sustainable urban travel and carbon emissions reduction. However, the sustainability of DBSPs is increasingly being challenged as various issues associated with different stakeholders emerge. While numerous studies have focused on the barriers to traditional bike-sharing programs, the sustainability performance of new-generation DBSPs is largely overlooked. It is accordingly imperative to understand the primary challenges that impede the sustainability of DBSPs and to consider what stimulative measures can be taken. In this study, we investigate the factors that are critical to DBSPs' sustainability from a network perspective. Stakeholder-associated factors and their interrelations were identified via literature analysis and interviews, and the social network analysis (SNA) method was employed to recognize the critical factors and links in DBSPs. As a result, 10 critical factors and 10 major interactions were identified and further classified into six challenges. Sharing transport schemes, legislative perfection, public private partnership (PPP), and product lifecycle management (PLM) were proposed to govern these challenges. This paper contributes to the existing body of knowledge of bike-sharing programs via a network approach that integrates the key influencing factors with those factors' associated stakeholders. Furthermore, these findings provide the government and operators with implications for mitigating the tough challenges and facilitating the sustainability of DBSPs.
\end{abstract}

Keywords: critical factors; dockless bike-sharing; sustainability; stakeholder-oriented; social network analysis; sharing transport; Mobike; Ofo; governance

\section{Introduction}

For the past three years, the fourth-generation of dockless bike-sharing programs (DBSPs, e.g., Mobike and Ofo) have experienced a rapid expansion and a boom period in China [1,2]. By March, 2017, the scale of the supply of dockless bikes for sharing in Chinese cities had reached over 4 million, and Shanghai alone had reached about 450,000 [3]. While Mobike became the world's biggest operator of DBSPs in December, 2016, Ofo had secured over 20 million users by March, 2017 [1]. Compared with traditional bike-sharing programs, DBSPs integrate mobile payment and global positioning system (GPS) tracking into the system, these features greatly increase the ease of use and management of DBSPs [4]. When using bike-sharing, urban dwellers not only ease the travel problem of "the last mile", but they can also achieve the financial savings, health benefits, and a low-carbon lifestyle. However, with the large-scale deployment of shared bicycles in Chinese cities, issues such as theft and vandalism, 
uncontrolled parking and waste accumulation are gradually surfacing. These issues are increasingly impeding the future development of DBSPs. Local governments in Beijing, Shanghai and other Chinese cities have forced operators to discontinue the bike-sharing supply programs. In this context, the promise of DBSPs being a means to facilitate sustainable urban travel and reduce carbon emissions is seen as a paradox [5]. How to address these problems is critical to achieve dockless bike-sharing sustainability.

In order to address the market failure of DBSPs, the central government of China launched a policy in August 2017. The aim of the policy is to strengthen bicycle-parking management (e.g., the construction of bike lanes and parking spots), implement the real-name system for users registration, and encourage social supervision and public opinion, thus forming a coordinated governance situation among governments, operators, social organizations and the public [6]. Social media and experts have repeatedly called on DBSPs operators to address the bike-sharing issues of waste recycling, deposit refunds and so on. Nevertheless, because dockless bike-sharing programs involve a complex social network, a variety of stakeholders have been influenced, and the interrelationships between them are also complex $[7,8]$. At this time, there are still no effective measures in place to make the development of DBSPs more sustainable [4].

Numerous studies have investigated the influencing factors associated with bike sharing. These studies have largely focused on the perspectives of usage behavior and choice intention $[9,10]$. Although scholars such as Fishman and Chardon have investigated the barriers, facilitators and determinants to the sustainable development of traditional bike-sharing schemes [11-13], these factors have changed in new-generation bike-sharing. They have also not considered the linkage between those influencing factors and stakeholders during the analysis procedure. Since the fourth-generation bike-sharing programs have been integrated with public transit systems and involved various stakeholders [1], the relationships between critical stakeholders and influencing factors should be afforded sufficient attention. It is therefore necessary to re-identify the critical factors that challenge DBSPs' sustainability and consider what stimulative measures can be taken from a stakeholder network perspective.

The main objectives of this study are: (1) to examine the critical factors that affect or impede the sustainability of DBSPs, from the perspective of stakeholders; and (2) to propose corresponding strategies to address the challenges encountered in the management of DBSPs. To achieve these research goals we employ the social network analysis (SNA) method, which is used to model organization structure and analyze interactions in complex social environments, in order to investigate the critical factors and those factors' interactions in DBSPs. This paper can provide implications and suggestions for local governments and operators on how to mitigate the existing challenges and facilitate the sustainable development of DBSPs. Furthermore, this study contributes to the existing body of knowledge of bike sharing via a network approach, integrating the critical influencing factors with their associated stakeholders.

The paper is organized as follows. Section 2 lays out the literature review and background of bike-sharing. Section 3 elaborates the methodology, data collection and processing. Section 4 presents the research results, which include network level, node and link level results. Critical factors are discussed, and corresponding management strategies are given in Section 5. The final section concludes this paper.

\section{Literature Review}

\subsection{Developmental Process of DBSPs}

The increasing attention being paid to global energy and climate change has given rise to growing interest in sustainable transportation alternatives [14]. Since the first-generation of bike sharing programs, namely the "White Bike", emerged in Amsterdam in 1965, bike sharing has experienced a dramatic growth and development in Europe, North America, South America, and Asia [15]. 
Numerous studies have been conducted to investigate the impact of bike-sharing programs, both in terms of implementation and operation [16]. There is a growing consensus that bike-sharing systems could bring about benefits such as time savings for travelers [4,17], mitigating congestion [1,18], promoting a healthier lifestyle [19,20], and reducing air and noise pollution [21]. Nevertheless, research has also indicated that bike-sharing programs have typically had significantly low usage rates. Scholars such as Fishman et al. and Shen et al. argued that due to the constraints caused by the number of urban docking stations, many users of bike-sharing schemes only use them for leisure purposes, but not for commuting [4,12].

In this context, many scholars began to worry about the negative externalities of bike sharing. For instance, with the increasing number of docking stations, the ancillary facilities would occupy public space and subsequently cause road congestion [22]. For the past several years, the usage rates of public bike sharing services have been declining in almost all countries that have bike-sharing systems [21]. This was the case until 2015, when the emergence of the fourth generation of products in China settled a series of problems. These fourth-generation dockless bike-sharing programs (DBSPs) integrate mobile payments and GPS tracking into the system, thus greatly increasing the ease of use and management [4]. For example, since the docking station is not required, users could not only order service and complete the payment through the smart phone application, but they can also find nearby bicycles based on the GPS installed on users' mobile phone and bikes [4]. These bicycles can be parked in the place where the bike is allowed to park, thus the scale of supply is also not limited by the capacity of docking station. Therefore, the supply quantity of bike sharing is much larger than that of traditional public bicycles, which is greatly convenient to the users. However, a combination of virtually unlimited bike sharing supply and immature management systems caused widespread challenges to the success of even the new DBSPs. Although it is undoubtedly important to investigate the factors that profoundly affect the realization of DBSPs sustainability, there have been few such studies conducted to consider this issue. As a result, this paper aims to bridge the research gap.

\subsection{Influencing Factors and Stakeholders Related to the Sustainability of DBSPs}

In terms of traditional public bike-sharing systems, researchers have identified numerous factors affecting bike-sharing usage levels and users' degree of satisfaction. One study found that bike-sharing usage is strongly correlated with the planning of city cycleways and docking stations. Also, most users' cycling behavior depends on the free ride time of public bike-sharing systems [23]. Another study also found that suffering from a lack of ancillary, urban cycling facilities significantly impacts the usage of bicycles, and in addition, the interminable sign-up process and mandatory helmet legislation lessen the spontaneity of cycling [11]. A study by Sun et al. claimed that traffic accidents and congestion, public transit accessibility and violent crime would influence the usage of public bike-sharing services [24]. With regard to the new-generation of DBSPs, Shen et al. investigated bicycle usage in Singapore. Shen's study found that the fleet scale and built-up environment are positively associated with DBSPs' usage. As such, DBSP business models, safety and legislation, urban design and planning should all be intensively considered in future research [4]. The influencing factors mentioned in the above studies typically involve various stakeholders, who are either directly or indirectly affected by the implementation and operation of bike-sharing systems. These stakeholders mainly include the government, users, operators, manufacturers, the general public, and so forth.

Studies have also emphasized the constraints to achieve bike sharing sustainability. Godavarthy and Taleqani indicated that snow, freezing temperatures, and other adverse winter weather conditions are the biggest challenges for developing bike sharing systems in America. However, another study argued that the existence of university campuses and other mitigating barriers to the use of bicycle services by college students are keys to the success or failure of the bike-sharing programs. Temperatures, wind and precipitation also have significant impacts [25]. Although these studies help us to understand the various factors that restrict bike-sharing systems, the authors did not demonstrate how to mitigate those challenges or who the corresponding stakeholders are. 
Furthermore, Yahya revealed that while previous studies have identified the barriers of traditional docked bike-sharing systems, we see the necessity to re-identify and re-assess the critical challenges to achieve DBSPs sustainability [26]. Based on the case study analyses of bike-sharing programs in five cities of China, Zhang et al. pointed out that an exploration of the influencing factors associated with stakeholders should be considered as an imperative and significant step in the planning, implementation and completion of bike-sharing programs [8]. Based on the above discussion of existing literature, this study considers how to investigate the critical challenges to achieve dockless bike-sharing sustainability from a stakeholder perspective.

\section{Research Methodology and Processes}

\subsection{Methodology}

\subsubsection{SNA}

Since the social network analysis (SNA) method was introduced by Moreno in 1934, it has been widely applied in many research fields, including but not limited to risk management [27], construction project management [28], information management [29], and waste management [30]. A social network is defined as a specific set of linkages among a defined set of persons, with the additional property whereby the characteristics of these linkages as a whole may be used to interpret the social behavior of the people involved [31]. In terms of a dockless bike-sharing program, the SNA views such a system as a complex system comprised of various stakeholders and interrelationships. The aim of network analysis is to explore stakeholder-associated factors and their correlations within DBSPs. According to Chinowsky et al. (2008), the SNA method can use social graphs to visualize the complex and abstract relationships between multiple stakeholders [32]. The social network method is fundamentally different from the statistical analysis and behavioral science research methods [33]. Compared with other research methods, the SNA can explore critical factors through the pattern or structure of relative relationships and related stakeholders. In addition, the influence of stakeholder behaviors and interactions can be systematically quantified from the perspective of network [34]. However, SNA has not been employed in the area of bike-sharing programs, thus this study extends SNA application to a critical factors analysis of DBSPs sustainability.

In SNA, all nodes are encoded in the form of SxFy, where $x$ represents the number of stakeholders, and $y$ represents the factors related to this stakeholder. For example, S3F6 is the sixth influencing factor related to the third stakeholder. Nodes with different shapes represent factors related to different stakeholders, while different color nodes represent different categories of factors. The arrows in the network represent the relationship among factors, and the thickness indicates influence degree of the relationship. Furthermore, there are several indicators in SNA to measure the role of nodes and analyze the network, including density, degree of node, status centrality, brokerage, and betweenness centrality [33]. These indicators measure the factor network from different aspects.

\subsubsection{Research Framework}

Previous studies on risk management using SNA have normally followed a classical framework, including risk identification, risk evaluation, analysis of critical risks and stakeholders, and risk response [32,33]. The factor analysis approach encompasses a risk analysis, and to a certain extent, these two methods have analogous characteristics and analysis steps. Scholars such as Yu et al. and Zheng et al. indicated that integrating a traditional framework with the SNA method can also effectively identify key influencing factors and various stakeholder interactions in other complex programs $[26,27]$. Therefore, this paper constructs a research framework according to the proposals of the above-named scholars. The primary steps for this study are: (1) identifying both the factors that affect DBSPs sustainability and the corresponding stakeholders; (2) estimating the influencing factors 
among different stakeholders; (3) conducting an analysis of critical factors and stakeholders; and (4) developing corresponding management strategies. The detail framework is shown in Figure 1.

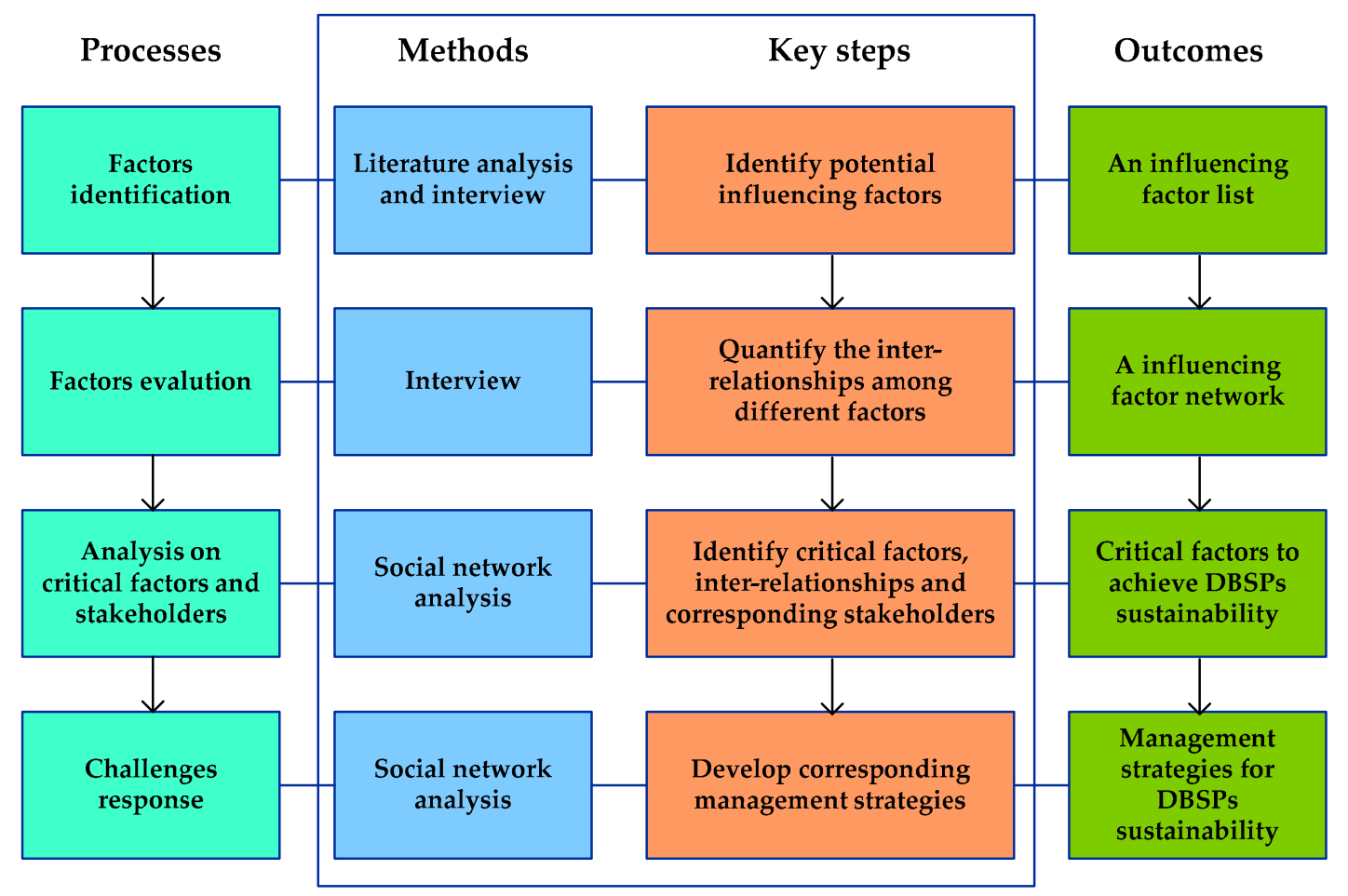

Figure 1. Research framework.

\subsection{Processes}

\subsubsection{Data Collection}

Interviews refer to the face to face communication between investigators and interviewees. On the one hand, open discussion can enable both sides to acquire a mass of information and mitigate ambiguity. On the other hand, information sharing between different participants can significantly improve data validity [35]. Considering that this study is conducted from a stakeholder perspective, interviews hence also follow a stakeholder-oriented sampling principle [36]. Stakeholders are persons who can influence the realization of an organization's goal, or all individuals and groups affected by organization's goal process [37]. According to the analysis in Section 2.2, users (S1), governments (S2), operators (S3), manufacturers (S4), and members of the general public (S5) were recognized as critical stakeholder groups in DBSPs. To ensure data representativeness and prevent the occurrence of biased judgement, we conducted interviews with all five stakeholder groups. In addition, this survey required S1 interviewees to have more than two years of experience in using DBSPs. Also, S2 interviewees must come from a government traffic management department and must also have been involved in the management of bike-sharing programs. Operation managers and customer service executives of dockless bike-sharing corporations were the main interviewees of the S3 group, the reason for selection is that they receive and discover the most problems on bikes-haring. In order to find the most suitable interviewees, S4 members were mainly introduced by S3, and there is a strong cooperative relationship between them. Considering the professionalism of this interview, the S5 interviewees were selected from expert groups or members of the public who expressed an interest in bike sharing. Initially, we identified several familiar interviewees from the five stakeholder groups, and then a snowball sampling approach was conducted to invite more stakeholders to take part in this survey. We initially contacted 58 stakeholders in total, but 19 of them were not interested in our study, and another nine 
invitees explained that they were not eligible to participate in the survey. Ultimately, 30 invitees were identified as qualified interviewees (with six members in each stakeholder group). The sample size meets the requirement of data analysis in terms of previous studies [27,36].

Before the formal interview was conducted, we sent the background information and content of this study to all interviewees via e-mail, in order to help prepare them for answering follow-up questions. At the same time, interviewees were also asked to respond to the following questions: (1) What factors do you think may affect the sustainability of DBSPs? (2) Can you suggest additional factors that are not included in the indicator list (i.e., indicators summarized by the literature shown in Table 1)? (3) Which of these factors may be relevant to you? Based on our literature review and the replies to the above questions, we modified the factors and formed an integrated system containing influencing factors and the corresponding stakeholders as shown in Table 1.

After completing the above work, interviewees were invited to semi-structured face-to-face interviews, in order to identify the potential connections between the influencing factors. The advantage of a semi-structured interview is that the interviewers can make necessary adjustments flexibly according to the actual situation, and the interviewees can choose the appropriate time and place to complete the interview carefully [35], Hence, the semi-structured interview can effectively improve the accuracy and authenticity of interview data.

Table 1. Influencing factors and corresponding stakeholders.

\begin{tabular}{|c|c|c|c|c|c|}
\hline $\begin{array}{l}\text { Factor } \\
\text { ID }\end{array}$ & $\begin{array}{l}\text { Stakeholder } \\
\text { Node }\end{array}$ & $\begin{array}{l}\text { Factors } \\
\text { Node }\end{array}$ & Influencing Factors & References & Category \\
\hline S1F1 & S1 & \multirow{2}{*}{ F1 } & \multirow{2}{*}{ Layout of urban road system } & \multirow{2}{*}[10,38]{} & \multirow{2}{*}{$\mathrm{C} 1$} \\
\hline S5F1 & S5 & & & & \\
\hline S1F2 & S1 & \multirow{2}{*}{ F2 } & \multirow{2}{*}{ Urban traffic accessibility } & \multirow{2}{*}{ [12] } & \multirow{2}{*}{$\mathrm{C} 1$} \\
\hline S5F2 & S5 & & & & \\
\hline S1F3 & S1 & \multirow{2}{*}{ F3 } & \multirow{2}{*}{ Cycling facilities construction } & \multirow{2}{*}[4,11]{} & \multirow{2}{*}{$\mathrm{C} 1$} \\
\hline S2F3 & S2 & & & & \\
\hline S3F4 & S3 & F4 & Layout of parking places & {$[11,13]$} & $\mathrm{C} 2$ \\
\hline S3F5 & S3 & F5 & Supply quantity of bike sharing & {$[39,40]$} & $\mathrm{C} 2$ \\
\hline S1F6 & S1 & F6 & $\begin{array}{c}\text { Serviceability safety } \\
\text { (e.g., product quality and standard) }\end{array}$ & {$[25,41]$} & $\mathrm{C} 3$ \\
\hline S1F7 & S1 & \multirow{2}{*}{ F7 } & \multirow{2}{*}{ Cost of using unit } & \multirow{2}{*}{ [40] } & \multirow{2}{*}{$\mathrm{C} 3$} \\
\hline S3F7 & S3 & & & & \\
\hline S1F8 & S1 & \multirow{2}{*}{ F8 } & \multirow{2}{*}{ Using cash pledges } & \multirow{2}{*}[25]{} & \multirow{2}{*}{$\mathrm{C} 3$} \\
\hline S3F8 & S3 & & & & \\
\hline S1F9 & S1 & F9 & $\begin{array}{c}\text { Convenience of use } \\
\text { (e.g., sign-up process and unlocking) }\end{array}$ & {$[11,38,41]$} & $\mathrm{C} 3$ \\
\hline S1F10 & S1 & F10 & Using comfortable capability & {$[41,42]$} & $\mathrm{C} 3$ \\
\hline S2F11 & $\mathrm{S} 2$ & \multirow{2}{*}{ F11 } & \multirow{2}{*}{ Urban built-up environment } & \multirow{2}{*}[4,22]{} & \multirow{2}{*}{$\mathrm{C} 1$} \\
\hline S5F11 & S5 & & & & \\
\hline S5F12 & S5 & F12 & Public commuting preferences & [43] & $\mathrm{C} 4$ \\
\hline S5F13 & S5 & F13 & Public low-carbon awareness & [38] & $\mathrm{C} 4$ \\
\hline S1F14 & S1 & F14 & Normative awareness of users & [2] & $\mathrm{C} 4$ \\
\hline S4F15 & S4 & F15 & Production innovation & Interview & C5 \\
\hline S3F16 & S3 & \multirow{3}{*}{ F16 } & \multirow{3}{*}{$\begin{array}{c}\text { Parking management } \\
\text { (e.g., service, cleaning and tidying) }\end{array}$} & \multirow{3}{*}[13,42]{} & \multirow{3}{*}{ C5 } \\
\hline S4F16 & $\mathrm{S} 4$ & & & & \\
\hline S5F16 & S5 & & & & \\
\hline S3F17 & S3 & \multirow{2}{*}{ F17 } & \multirow{2}{*}{ Scrap rate of bike-sharing products } & \multirow{2}{*}{ Interview } & \multirow{2}{*}{$\mathrm{C} 5$} \\
\hline S4F17 & S4 & & & & \\
\hline
\end{tabular}


Table 1. Cont.

\begin{tabular}{|c|c|c|c|c|c|}
\hline $\begin{array}{l}\text { Factor } \\
\text { ID }\end{array}$ & $\begin{array}{l}\text { Stakeholder } \\
\text { Node }\end{array}$ & $\begin{array}{l}\text { Factors } \\
\text { Node }\end{array}$ & Influencing Factors & References & Category \\
\hline S3F18 & S3 & \multirow{2}{*}{ F18 } & \multirow{2}{*}{ Theft and vandalism behavior } & \multirow{2}{*}{ Interview } & \multirow{2}{*}{$\mathrm{C} 5$} \\
\hline S5F18 & S5 & & & & \\
\hline S3F19 & S3 & F19 & Retrieving waste bike sharing & {$[44,45]$} & $\mathrm{C} 5$ \\
\hline S4F20 & S4 & F20 & Waste recycling and reusing & {$[44,45]$} & $\mathrm{C} 5$ \\
\hline S1F21 & S1 & \multirow{3}{*}{ F21 } & \multirow{3}{*}{ Efficient legislation and supervision } & \multirow{3}{*}{ [4] } & \multirow{3}{*}{ C6 } \\
\hline $\mathrm{S} 2 \mathrm{~F} 21$ & S2 & & & & \\
\hline S3F21 & S3 & & & & \\
\hline S2F22 & S2 & \multirow{2}{*}{ F22 } & \multirow{2}{*}{$\begin{array}{l}\text { Government's incentives and subsidies } \\
\text { for enterprise }\end{array}$} & \multirow{2}{*}[39,46]{} & \multirow{2}{*}{ C6 } \\
\hline S3F22 & S3 & & & & \\
\hline S2F23 & S2 & \multirow{2}{*}{ F23 } & \multirow{2}{*}{$\begin{array}{l}\text { Enterprise cooperation with government } \\
\text { (e.g., PPP mode) }\end{array}$} & \multirow{2}{*}[40]{} & \multirow{2}{*}{ C6 } \\
\hline S3F23 & S3 & & & & \\
\hline S3F24 & S3 & \multirow{2}{*}{ F24 } & \multirow{2}{*}{ Bike-sharing market competition } & \multirow{2}{*}{ Interview } & \multirow{2}{*}{$\mathrm{C} 7$} \\
\hline S4F24 & S4 & & & & \\
\hline S2F25 & S2 & \multirow{3}{*}{ F25 } & \multirow{3}{*}{ Corporate social responsibility } & \multirow{3}{*}{ Interview } & \multirow{3}{*}{$\mathrm{C} 8$} \\
\hline S3F25 & S3 & & & & \\
\hline S4F25 & S4 & & & & \\
\hline S3F26 & S3 & F26 & Profit model of DBSPs & [4] & $\mathrm{C} 7$ \\
\hline S2F27 & S2 & \multirow{2}{*}{ F27 } & \multirow{2}{*}{$\begin{array}{l}\text { Integrating dockless bike sharing with } \\
\text { public transportation }\end{array}$} & \multirow{2}{*}[4,18]{} & \multirow{2}{*}{$\mathrm{C} 6$} \\
\hline S5F27 & S5 & & & & \\
\hline S1F28 & S1 & \multirow{3}{*}{ F28 } & \multirow{3}{*}{ Urban air quality } & \multirow{3}{*}[10,11,23]{} & \multirow{3}{*}{$\mathrm{C} 1$} \\
\hline S2F28 & S2 & & & & \\
\hline S5F28 & S5 & & & & \\
\hline
\end{tabular}

To ensure (as much as possible) the accuracy of the interviewees' opinions, we gave a detailed verbal explanation of each factor. In SNA, the node represents the identified factor, and the link refers to the influence of one factor on other factors. Interviewees were requested to clearly identify the direction of the potential impact, because the relationship could be reciprocal. For instance, if there is a link from SmFn to SxFy, this demonstrates that SmFn can affect SxFy, and then corresponding stakeholder groups Sm and Sx will be required to evaluate the association between SmFn and SxFy.

Therefore, there were three types of questions in this assessment: (a) In the development process of DBSPs, can SmFn influence SxFy (i.e., judging the direction of the link)? (b) What is the likelihood of such a potential impact (the likelihood of this link)? (c) If SmFn affects SxFy, to what extent (degree of influence)? Following a similar study conducted by Yu et al. [27] and $\mathrm{Li}$ et al. [36], a five-level Likert scale (where " 1 " and " 5 ", respectively, means the lowest and the highest level) was used by interviewees to answer questions (b) and (c). The integrated influence level of a link (P) is expressed by multiplying the likelihood rating with the degree of influence.

\subsubsection{Data Processing}

Normally, a comparative analysis of the data obtained from such interviews would reveal that some stakeholders corresponding to the link did not reach a consensus on the score $(0 \leq \mathrm{P} \leq 25)$ of this link. That is different stakeholders have different evaluation on criterion on some links. In this case, it is necessary to determine whether or not a reevaluation is needed. We determine this by calculating the degree of variation of P. According to the calculation and judgement method for degree of variation $[27,47], \mathrm{V}=\left(\mathrm{P}_{\max }-\mathrm{P}_{\min }\right) / 25$. If $\mathrm{V} \leq 0.2$, this means the degree of variation is acceptable, and then the median of the assessment result can be used to reflect the integrated influence level of the link. Conversely, if $\mathrm{V}>0.2$, the interviews with relevant stakeholders need to be conducted again until 
an acceptable result is produced. As a result, we conducted another online conference through QQ (a social software application developed by Tencent) and obtained the final data of this study.

According to previous studies that used the SNA method [36,48,49], the six indicators of network density, network cohesion, nodal degree, betweenness centrality, status centrality, and brokerage were typically employed to present the critical features of the network, and then to recognize key factors and interactions. Following the interviews, we imported the collected data into NetMiner 4, in order to calculate the above mentioned six indicators, and to recognize the critical factors, links, and the associated stakeholders.

\section{Research Results}

A total of 28 factors and 48 network nodes affecting the sustainability of DBSPs were identified in the previous literature review and email interviews, as shown in Table 1. These factors and network nodes eventually formed 255 links via subsequent face-to-face interviews. According to the characteristics of these factors and the results of the interview, we further divided the identified 28 factors into eight categories, which are environment (C1), planning (C2), perception (C3), preference (C4), life-cycle (C5), governance (C6), business (C7), and responsibility (C8), respectively.

\subsection{Network Level Results}

The network level analysis using NetMiner 4 is shown in Figure 2. Here, the influence factor network consists of 48 nodes and is connected by 255 links. The color and shape of the nodes, respectively, represent the categories of stakeholders and factors. The arrow shows that there is an impact relationship between a pair of stakeholder-related factors, and the thickness of the arrow represents the degree of impact. The influencing factors with more links are at the center of the network, while the nodes with fewer links are closer to the network boundary. The influencing factors network structure provides researchers with clear visual insights. The numerous arrows in Figure 2 indicate that there are many causal relationships between stakeholders, which means that small changes will affect all factors in the entire network. The network density is 0.113 , and the average distance between nodes is 2.937. This finding indicates that the network is intensive, and the factors are closely related to each other. The challenges caused by these influencing factors will therefore be very complicated and difficult to govern. The presence of multiple green nodes at the center of the network indicates that the performance of operators plays a crucial role in the sustainable development of DBSPs. At the same time, interactions with these green nodes in the network also occupy most of the existing links. Considering that there are currently no unified control policies and management measures in place for DBSPs in China, the problems being exposed for bike sharing are largely caused by the operators' business behavior. This may be the primary reason why factors associated with operators are mainly distributed in the center of the network map.

\subsection{Node and Link Level Results}

In order to recognize the key factors that influence the sustainability of DBSPs, we analyzed the direct and indirect propagation effects of single nodes. The status centrality map that contains all factors is shown in Figure 3; it shows the effect of each factor on the whole. Normally, factors at the center of the map have a momentous effect on the network. Many green nodes are located at the center of the map, which means that operators play an important role in the running and success of DBSPs. In addition, there is a yellow node in the center (i.e., S5F12, public commuting preferences). In the related study, Fishman et al. and Shen et al. found that many users of bike-sharing services only use them for leisure, but not for commuting [4,12]. Therefore, public commuting preferences, (that is, the habits of selecting tools for transportation), will greatly influence the sustainability of DBSPs. 


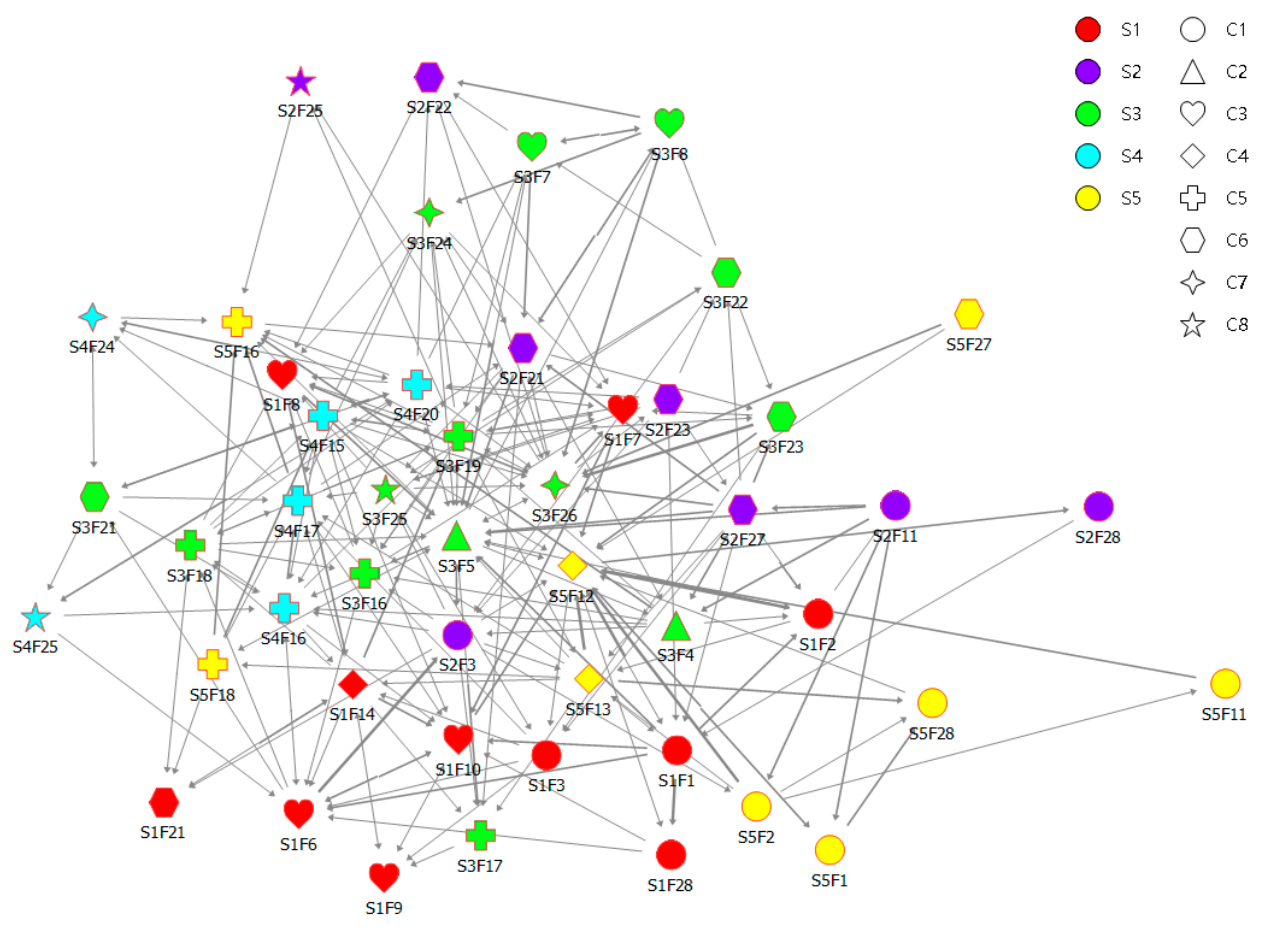

Figure 2. Stakeholder-associated influencing factors network.

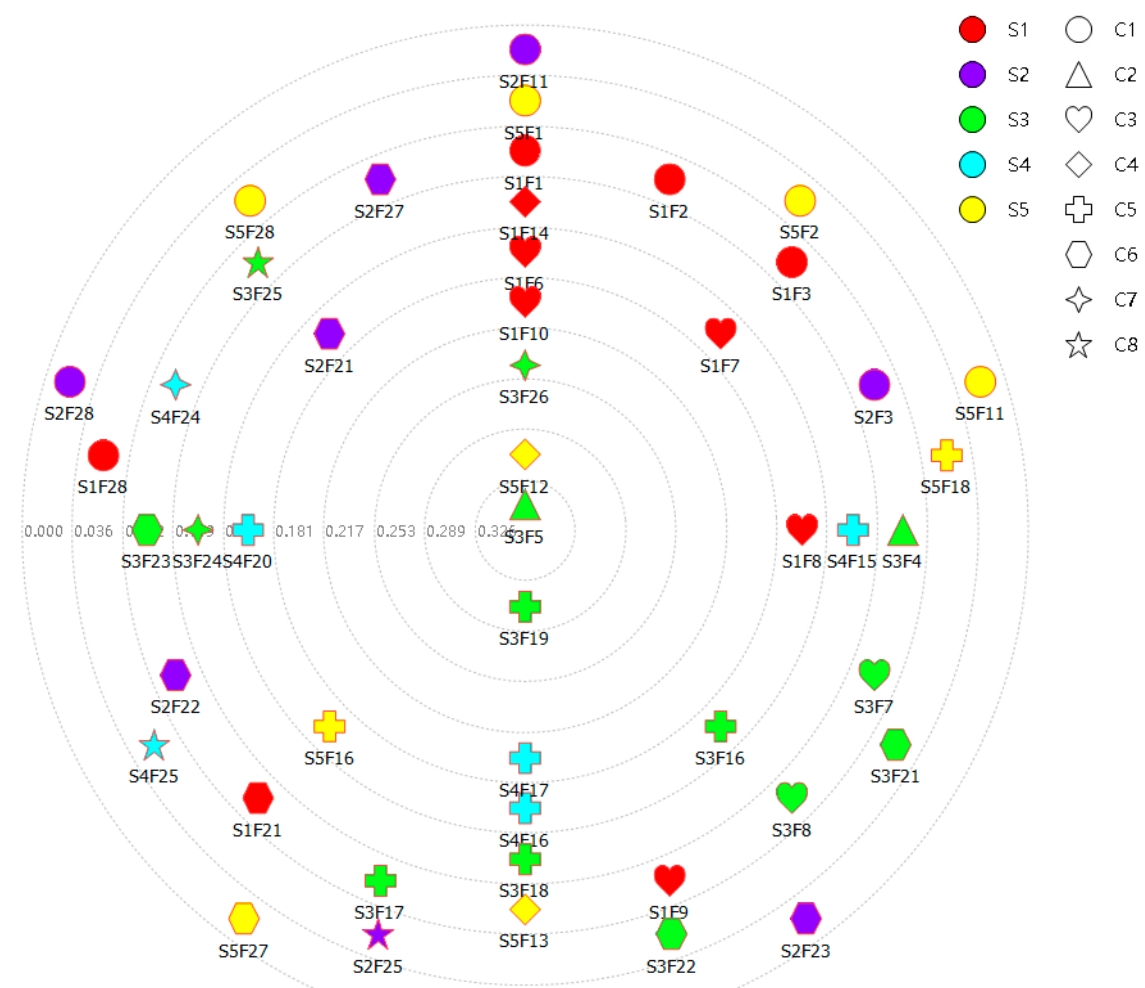

Figure 3. Influencing factors distribution on the status centrality map.

In addition to the status centrality map, previous scholars proposed using multiple indicators to measure the roles of nodes in the network, including out degree, degree difference, out status centrality and ego size $[48,49]$. These indicators show the importance of factor nodes from different angles. Table 2 lists the top 10 factors for these indicators. From this, we find that there are several factors ranking 
high even in different indicators, such as S3F19 (retrieving waste bike sharing), S3F5 (supply quantity of bike sharing), S5F12 (public commuting preferences) and S4F20 (waste recycling and reusing), which indicates that these factors are critical to the entire network.

Table 2. Top factors based on ego network, status centrality and degree analyses (In Tables $2-4$, the bold ID are ultimately identified as critical factors and links).

\begin{tabular}{|c|c|c|c|c|c|c|c|c|}
\hline Ranking & $\begin{array}{l}\text { Factor } \\
\text { ID }\end{array}$ & $\begin{array}{c}\text { Out } \\
\text { Degree }\end{array}$ & $\begin{array}{l}\text { Factor } \\
\text { ID }\end{array}$ & $\begin{array}{c}\text { Degree } \\
\text { Difference }\end{array}$ & $\begin{array}{l}\text { Factor } \\
\text { ID }\end{array}$ & $\begin{array}{l}\text { Out Status } \\
\text { Centrality }\end{array}$ & $\begin{array}{l}\text { Factor } \\
\text { ID }\end{array}$ & Ego Size \\
\hline 1 & S3F19 & 15 & S5F12 & 9 & S3F19 & 1.5 & S3F5 & 23 \\
\hline 2 & S3F5 & 13 & S5F16 & 7 & S4F20 & 1.4 & S3F19 & 21 \\
\hline 3 & S4F20 & 13 & S1F8 & 6 & S3F5 & 1.3 & S5F12 & 17 \\
\hline 4 & S2F21 & 10 & S4F20 & 6 & S2F27 & 1.3 & S3F26 & 16 \\
\hline 5 & S4F15 & 10 & $\mathrm{~S} 2 \mathrm{~F} 23$ & 6 & S2F21 & 1.1 & S4F17 & 15 \\
\hline 6 & S3F26 & 10 & S2F27 & 6 & S3F26 & 1.0 & S4F20 & 15 \\
\hline 7 & S2F27 & 10 & S1F7 & 6 & S4F15 & 1.0 & S2F21 & 14 \\
\hline 8 & S5F13 & 9 & S1F10 & 6 & S5F13 & 0.9 & S5F13 & 13 \\
\hline 9 & S2F3 & 8 & S3F5 & 4 & S1F1 & 0.9 & S4F15 & 13 \\
\hline 10 & S1F14 & 8 & S2F11 & 4 & S3F18 & 0.8 & S4F16 & 13 \\
\hline
\end{tabular}

Brokerage is a comprehensive evaluation index used to consider node partitions. For each node, the index counts the number of times each node is counted in five kinds of brokerage relationships, encompassing coordinator, gatekeeper, representative, itinerant and liaison [50]. Table 3 lists the top 10 nodes in the brokerage analysis. These nodes play a crucial role in bridging the stakeholder groups, so these factors are also critical to the sustainability of DBSPs.

Table 3. Top stakeholder-associated factors based on brokerage analysis.

\begin{tabular}{|c|c|c|c|c|c|c|c|}
\hline Ranking & Factor ID & Coordinator & Gatekeeper & Representative & Itinerant & Liaison & Total \\
\hline 1 & S3F5 & 35 & 56 & 41 & 8 & 40 & 180 \\
\hline 2 & S3F19 & 30 & 40 & 35 & 10 & 42 & 157 \\
\hline 3 & S5F12 & 5 & 9 & 28 & 14 & 24 & 80 \\
\hline 4 & S3F26 & 9 & 7 & 29 & 6 & 22 & 73 \\
\hline 5 & S4F20 & 5 & 14 & 23 & 8 & 12 & 62 \\
\hline 6 & S2F21 & 0 & 0 & 6 & 31 & 18 & 55 \\
\hline 7 & S4F17 & 1 & 6 & 6 & 9 & 26 & 48 \\
\hline 8 & S4F15 & 3 & 9 & 10 & 7 & 11 & 40 \\
\hline 9 & S4F17 & 2 & 4 & 11 & 5 & 15 & 37 \\
\hline 10 & S5F13 & 1 & 10 & 6 & 3 & 15 & 35 \\
\hline
\end{tabular}

Eventually, in order to measure the ability of a factor or interaction controlling other effects in the network, we took stock of the betweenness centrality of different nodes and links. The top 10 are considered crucial and are shown in Table 4. To some extent, addressing the challenges caused by the abovementioned factor nodes or interactions can significantly increase the sustainability of DBSPs.

Table 4. Critical influencing factors and links based on the betweenness centrality.

\begin{tabular}{ccccc}
\hline Ranking & Factor ID & $\begin{array}{c}\text { Node betweenness } \\
\text { Centrality }\end{array}$ & Link ID & $\begin{array}{c}\text { Link betweenness } \\
\text { Centrality }\end{array}$ \\
\hline 1 & S3F5 & 0.276 & S5F12 $\rightarrow$ S3F5 & 186.585 \\
2 & S5F12 & 0.187 & S5F16 $\rightarrow$ S2F21 & 98.938 \\
3 & S3F19 & 0.155 & S3F5 $\rightarrow$ S2F3 & 94.374 \\
4 & S3F26 & 0.092 & S2F3 $\rightarrow$ S5F2 & 90.544 \\
5 & S2F21 & 0.076 & S3F5 $\rightarrow$ S1F2 & 81.077 \\
6 & S2F3 & 0.073 & S3F5 $\rightarrow$ S3F19 & 71.855 \\
7 & S1F6 & 0.064 & S3F26 $\rightarrow$ S2F23 & 67.774 \\
8 & S4F20 & 0.062 & S3F5 $\rightarrow$ S3F26 & 65.178 \\
9 & S1F14 & 0.048 & S1F6 $\rightarrow$ S2F3 & 64.027 \\
10 & S3F18 & 0.044 & S5F12 $\rightarrow$ S1F3 & 60.722 \\
\hline
\end{tabular}




\section{Critical Factors and Management Strategies}

\subsection{Critical Factors and Challenges to Achieve DBSPs Sustainability}

In Section 4, we analyzed the degree of network nodes, ego network, status centrality, brokerage, and betweenness centrality of each factor. Considering that the ranking of key factors based on different evaluation indicators may be slightly different, major studies using SNA tend to choose the top few factors from each ranking list as the key factors [28]. Undoubtedly, these factors are important in different aspects of the network. Eliminating these nodes and links could significantly reduce the degree of network complexity. Furthermore, factors that appear in more than three rankings should also be identified as critical, because they affect the entire factor network in many ways [27]. This means that the critical factors have multiple effects on the sustainability of DBSPs. In this study, we followed the above principles and ultimately determined 10 critical influencing factors and 10 important links for the sustainable development of DBSPs, as shown in Table 5. To more clearly understand these key factors and links, we classified them as six major challenges, and a brief explanation of each was given. The rationale of this classification is that, if one factor node of the 10 key factors and 10 key links selected exists in multiple links simultaneously, which means that it may lead to multiple problems, then this is a key challenge. If there are multiple factors or links that have certain relevance, they will be summarized as another challenge.

Table 5. Recognition of critical factors and challenges according to the integrated network indicators.

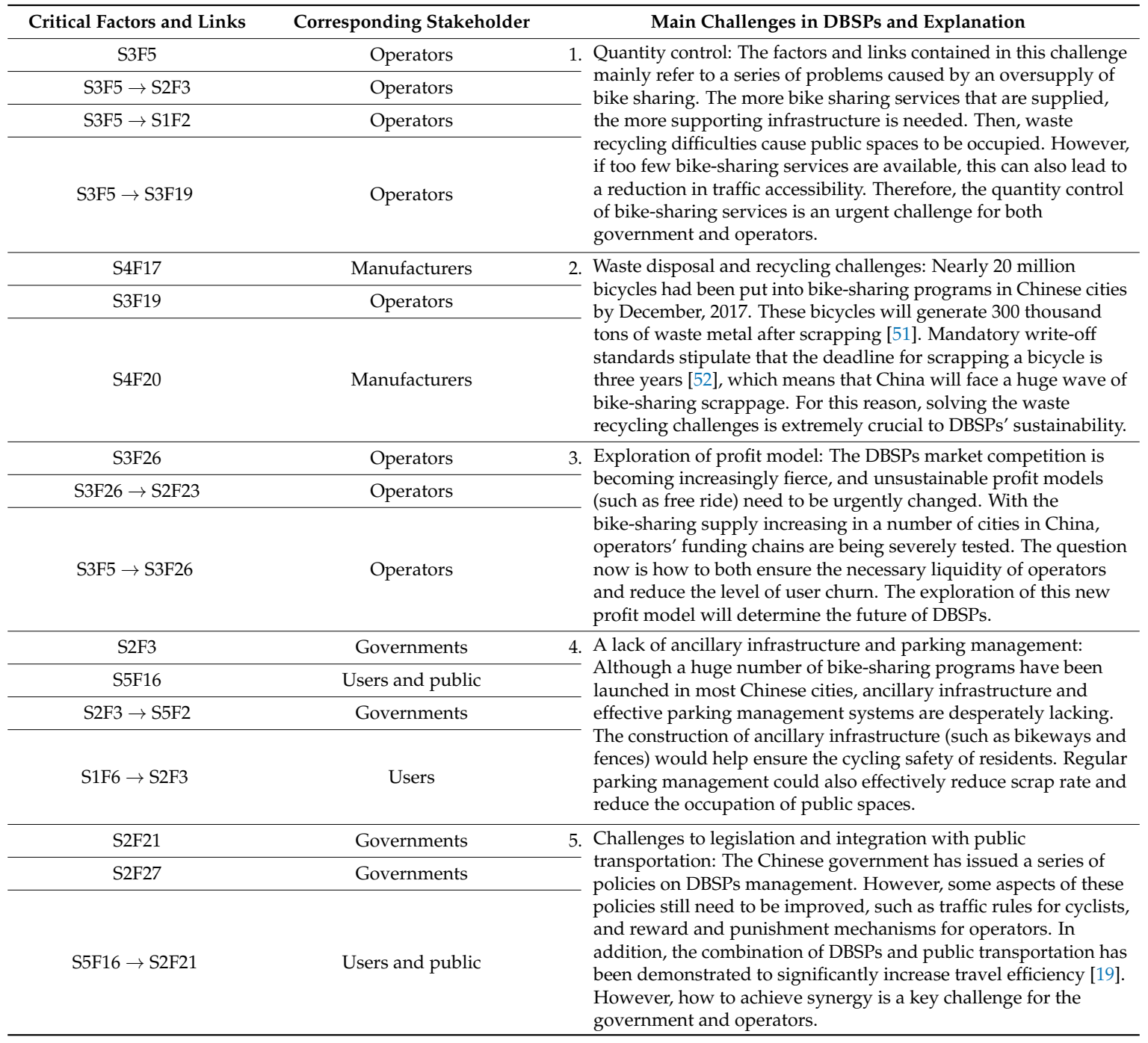


Table 5. Cont.

\begin{tabular}{|c|c|c|}
\hline Critical Factors and Links & Corresponding Stakeholder & Main Challenges in DBSPs and Explanation \\
\hline S5F12 & Users and public & \multirow{3}{*}{$\begin{array}{l}\text { 6. Commuting preferences of residents: The public's commuting } \\
\text { preferences affect the supply quantity of bike sharing, } \\
\text { the construction of ancillary infrastructure for cycling and even } \\
\text { the re-planning of road layouts. Research has found that many } \\
\text { users of bike sharing only use them for leisure, but not for } \\
\text { commuting [12]. Therefore, improving the public's commuting } \\
\text { preferences could greatly promote and improve the sustainability } \\
\text { of DBSPs. }\end{array}$} \\
\hline $\mathrm{S} 5 \mathrm{~F} 12 \rightarrow \mathrm{S} 3 \mathrm{~F} 5$ & Users and public & \\
\hline $\mathrm{S} 5 \mathrm{~F} 12 \rightarrow \mathrm{S} 1 \mathrm{~F} 3$ & Users and public & \\
\hline
\end{tabular}

\subsection{Management Strategies (MS) to Challenges Mitigation}

Based on the above analysis, we proposed four management strategies to settle the DBSPs challenge. Due to the fact that the government and operators are the primary enablers of DBSPs in China, these strategies are mainly based on the government's and operators' perspectives, including the sharing of transport schemes, legislative perfection, public private partnerships, and product life-cycle management. As a result, a governance framework consisting of critical factors and interactions, challenges, and management strategies was formed, as shown in Figure 4.

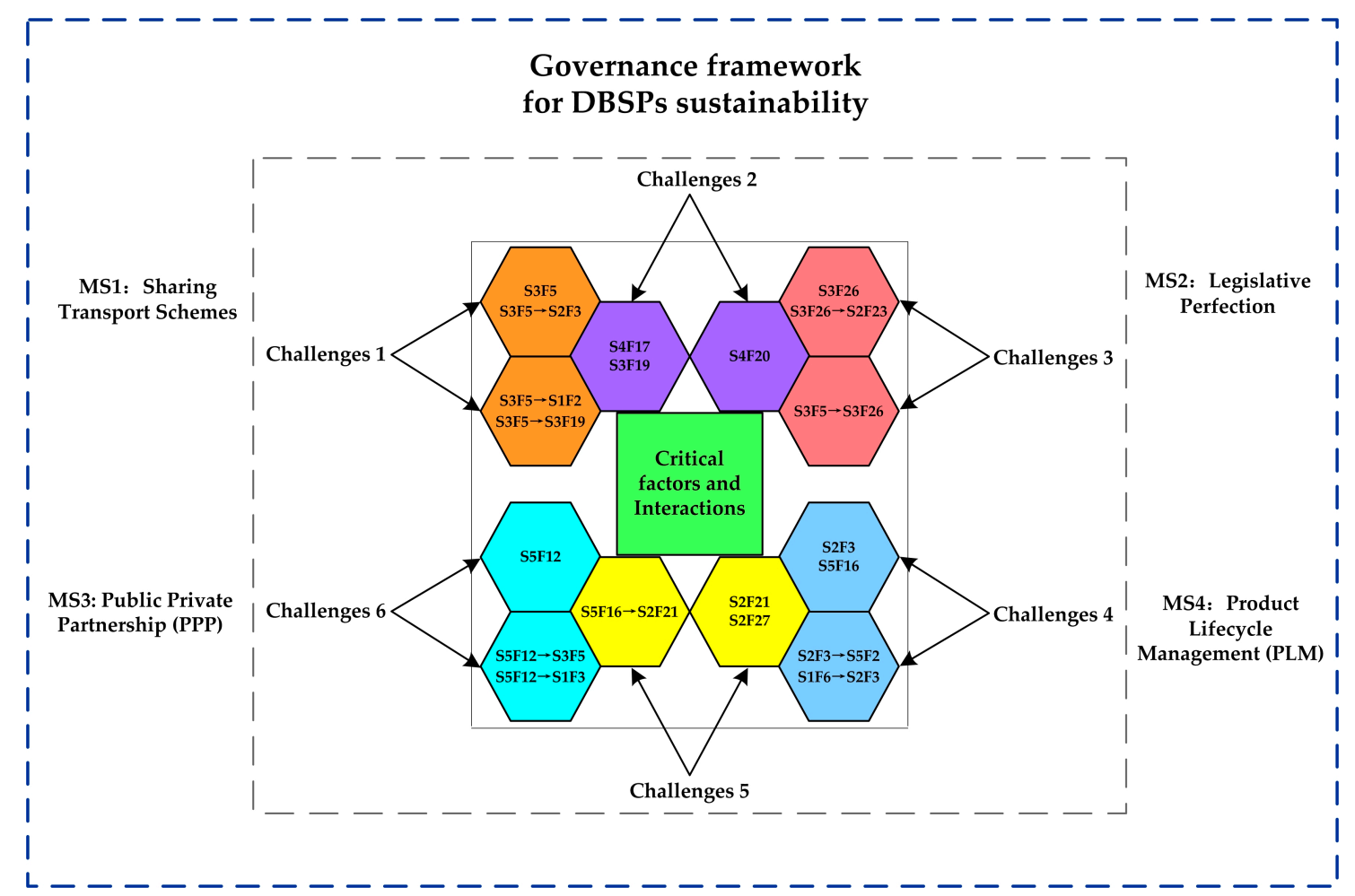

Figure 4. The framework for understanding critical factors, challenges and management strategies.

\section{- MS1: Sharing Transport Schemes}

Bike sharing has proven to be an effective tool for promoting sustainable transport. As a result of using bike sharing, urban dwellers not only solve the travel problem of "the last mile", but they can also achieve financial savings, health benefits, and a low-carbon lifestyle. From the perspective of government management, it is necessary to further promote DBSPs as a component of national transportation strategic planning. The advantage of doing this is that, on the one hand, the healthy development and re-planning of DBSPs in China's cities can be guaranteed. Therefore, Challenge 1 (quantity control of bike sharing) can be effectively mitigated. Additionally, the social position of DBSPs 
will be enhanced, which would enable residents to rethink their trip modes. As such, the residents' commuting preferences in Challenge 6 can also be addressed.

\section{- MS2: Legislative Perfection}

Although the Chinese government has issued a series of policies on DBSPs management, there are still no effective measures in place to make the development of dockless bike-sharing programs more resilient and sustainable [53]. Problems such as the excessive supply of bikes (highlighted in Challenge 1) and the cycling traffic regulations and reward and punishment mechanisms for operators (Challenge 5) need to be addressed through mandatory legislation and supervision. In addition, under certain traffic carrying capacity constraints, more effective policies and laws should be introduced, in order to promote the improvement of urban transportation sharing systems. For instance, the government could integrate all types of transportation software (including bus, subway, bike sharing and car sharing) into an information platform. At the same time, crucial traffic information (such as parking spaces, parking fees and license plate details) could be published on this platform, thereby helping to realize more effective information sharing and credit accumulation.

\section{- MS3: Public Private Partnership (PPP)}

A public-private partnership (PPP) is seen as a long-term, complex collaboration between the public and private sectors. Their purpose is to provide infrastructure and public services. As such, PPPs are widely used all over the world in the construction of sewage treatment, garbage disposal, highway and rail transit projects [54]. We suggest using a PPP model to develop DBSPs in China. The special purpose vehicle (SPV) initiative was jointly established by the government and the bike-sharing industry. The industry is responsible for market analysis, vehicle production and supply, and the government is responsible for providing supporting infrastructure and promoting the integration of DBSPs with public transportation. During this cooperation, the government and bike-sharing industry will share project risks and benefits, in order to achieve their common goal of improving DBSPs sustainability. Using this approach, Challenge 3 and Challenge 5 can be effectively governed.

\section{- MS4: Product Lifecycle Management (PLM)}

Product lifecycle management (PLM) refers to information and processes throughout the entire lifecycle of product management from the perspective of requirements, planning, design, production, marketing, use, maintenance and recycling [55]. Currently, parking management (i.e., maintenance), waste recycling and reuse are extremely lacking when it comes to bike sharing. To prevent bike sharing from going from sharing traffic to "sharing garbage", operators should design and perfect the downstream industrial chain of DBSPs from the perspective of PLM. Furthermore, in order to ensure that operators achieve the full life cycle management of DBSPs, the Chinese government should incorporate shared bicycles into the implementation scope of the extended production responsibility system. This would be considered to be an important means to achieve a sustainable circular recycling economy and could be widely used as part of Waste Electrical and Electronic Equipment (WEEE) management [56]. These strategies could play an important role in the mitigation of Challenge 2 and Challenge 4 .

\section{Conclusions}

The governance of DBSPs sustainability is complex, as this requires that various stakeholders, as well as multiple influencing factors, be associated with each other. As such, an increasing number of challenges caused by these complexities need to be addressed as a matter of urgency. This paper lists the factors that influence the sustainability of DBSPs (and corresponding stakeholders), based on both a literature review and interviews. In addition, social network analysis (SNA) was applied in order to examined the critical factors and links, which were in turn classified into the following six major 
challenges: (1) quantity control; (2) waste disposal and recycling challenges; (3) exploration of profit model; (4) a lack of ancillary infrastructure and parking management; (5) legislation and integration with public transportation; and (6) residents' commuting preferences. Considering that settling these challenges could obviously alleviate the current development bottleneck of DBSPs, we finally proposed four corresponding management strategies, namely sharing transport schemes, legislative perfection, public private partnership, and product life-cycle management.

These findings provide a useful reference for the Chinese government's traffic management department and bike-sharing operators to take appropriate measures to improve the sustainability of DBSPs. For instance, understanding the importance of waste disposal and recycling may capture the government's attention and encourage them to introduce more specific policies. Meanwhile, the manufacturers and operators could soon develop equipment and technologies for converting scrapped bicycles from bike-sharing programs. The study also contributes to the existing body of knowledge of the fourth generation of bike-sharing products and technologies, as well as their sustainable development, especially in China. As such, the methodology applied in this study could also be employed to analyze the critical factors and links in other shared economy projects, such as car-sharing and sharing accommodation.

The primary limitations of this study are that: (1) not all the stakeholder groups related with DBSPs were represented in our interviews. For example, taxi drivers and traditional bicycle manufacturers are also stakeholder groups associated with bike-sharing development. (2) Due to the complexity of looking for stakeholders and accessing data through interviews, the identification of critical factors and links was conducted only based on the cognition of 30 interviewees. Some potential factors influencing bike sharing sustainability may not, therefore, be covered. Thus, a more comprehensive range of stakeholder groups and a larger number of respondents should be invited to conduct follow-up studies.

Author Contributions: J.S. and H.S. conceived the study and completed the paper in English; Y.S. and J.L. participated in data collecting and drafting the article; G.W. revised it critically for important content.

Funding: This research received no external funding.

Acknowledgments: This study was supported by the Fundamental Research Funds for the Central Universities (22120170137).

Conflicts of Interest: The authors declare no conflicts of interest.

\section{References}

1. Wang, M.; Zhou, X. Bike-sharing systems and congestion: Evidence from US cities. J. Transp. Geogr. 2017, 65, 147-154. [CrossRef]

2. Lan, J.; Ma, Y.; Zhu, D.; Mangalagiu, D.; Thornton, T.F. Enabling value co-creation in the sharing economy: The case of mobike. Sustainability 2017, 9, 1504. [CrossRef]

3. iiMedia Research. 2017 Q1 China Renting Bicycle Market Research Report; iiMedia Consultation Group: Guangzhou, China, 2017.

4. Shen, Y.; Zhang, X.; Zhao, J. Understanding the usage of dockless bike sharing in Singapore. Int. J. Sustain. Transp. 2018, 8318, 1-15. [CrossRef]

5. Acquier, A.; Daudigeos, T.; Pinkse, J. Promises and paradoxes of the sharing economy: An organizing framework. Technol. Forecast. Soc. Chang. 2017, 125, 1-10. [CrossRef]

6. The Central People's Government of the China. Guidance for Bike-Sharing Development. Available online: http:/ / www.gov.cn/xinwen/2017-08/03/content_5215643.htm (accessed on 19 June 2018). (In Chinese)

7. Mateo-Babiano, I.; Kumar, S.; Mejia, A. Bicycle sharing in Asia: A stakeholder perception and possible futures. Transp. Res. Procedia 2017, 25, 4970-4982. [CrossRef]

8. Zhang, L.; Zhang, J.; Duan, Z.Y.; Bryde, D. Sustainable bike-sharing systems: Characteristics and commonalities across cases in urban China. J. Clean. Prod. 2015, 97, 124-133. [CrossRef]

9. Hazen, B.T.; Overstreet, R.E.; Wang, Y. Predicting public bicycle adoption using the technology acceptance model. Sustainability 2015, 7, 14558-14573. [CrossRef] 
10. Campbell, A.A.; Cherry, C.R.; Ryerson, M.S.; Yang, X. Factors influencing the choice of shared bicycles and shared electric bikes in Beijing. Transp. Res. Part Emerg. Technol. 2016, 67, 399-414. [CrossRef]

11. Fishman, E.; Washington, S.; Haworth, N. Barriers and facilitators to public bicycle scheme use: A qualitative approach. Transp. Res. Part Traffic Psychol. Behav. 2012, 15, 686-698. [CrossRef]

12. Fishman, E.; Washington, S.; Haworth, N.; Mazzei, A. Barriers to bikesharing: An analysis from Melbourne and Brisbane. J. Transp. Geogr. 2014, 41, 325-337. [CrossRef]

13. Médard de Chardon, C.; Caruso, G.; Thomas, I. Bicycle sharing system 'success' determinants. Transp. Res. Part Policy Pract. 2017, 100, 202-214. [CrossRef]

14. Ioppolo, G.; Cucurachi, S.; Salomone, R.; Saija, G.; Shi, L. Sustainable Local Development and Environmental Governance: A Strategic Planning Experience. Sustainability 2016, 8, 180. [CrossRef]

15. Shaheen, S.; Guzman, S.; Zhang, H. Bikesharing in Europe, the Americas, and Asia. Transp. Res. Rec. J. Transp. Res. Board 2010, 2143, 159-167. [CrossRef]

16. Ricci, M. Bike sharing: A review of evidence on impacts and processes of implementation and operation. Res. Transp. Bus. Manag. 2015, 15, 28-38. [CrossRef]

17. Fishman, E. Bikeshare: A Review of Recent Literature. Transp. Rev. 2016, 36, 92-113. [CrossRef]

18. Fishman, E.; Washington, S.; Haworth, N. Bike share's impact on car use: Evidence from the United States, Great Britain, and Australia. Transp. Res. Part Transp. Environ. 2014, 31, 13-20. [CrossRef]

19. Fishman, E.; Washington, S.; Haworth, N. Bike Share: A Synthesis of the Literature. Transp. Rev. 2013, 33, 148-165. [CrossRef]

20. Midgley, P. Bicycle-Sharing Schemes: Enhancing Sustainable Mobility in Urban Areas. Comm. Sustain. Dev. 2011, 24.

21. Shaheen, S.; Cohen, A.; Martin, E. Public Bikesharing in North America. Transp. Res. Rec. J. Transp. Res. Board 2013, 2387, 83-92. [CrossRef]

22. Burke, C.M.; Scott, D.M. The space race: A framework to evaluate the potential travel-time impacts of reallocating road space to bicycle facilities. J. Transp. Geogr. 2016, 56, 110-119. [CrossRef]

23. Mateo-Babiano, I.; Bean, R.; Corcoran, J.; Pojani, D. How does our natural and built environment affect the use of bicycle sharing? Transp. Res. Part Policy Pract. 2016, 94, 295-307. [CrossRef]

24. Sun, Y.; Mobasheri, A.; Hu, X.; Wang, W. Investigating impacts of environmental factors on the cycling behavior of bicycle-sharing users. Sustainability 2017, 9, 1060. [CrossRef]

25. Mattson, J.; Godavarthy, R. Bike share in Fargo, North Dakota: Keys to success and factors affecting ridership. Sustain. Cities Soc. 2017, 34, 174-182. [CrossRef]

26. Yahya, B.N. Overall bike effectiveness as a sustainability metric for bike sharing systems. Sustainability 2017, 9, 2070. [CrossRef]

27. Yu, T.; Shen, G.Q.; Shi, Q.; Lai, X.; Li, C.Z.; Xu, K. Managing social risks at the housing demolition stage of urban redevelopment projects: A stakeholder-oriented study using social network analysis. Int. J. Proj. Manag. 2017, 35, 925-941. [CrossRef]

28. Zheng, X.; Le, Y.; Chan, A.P.C.; Hu, Y.; Li, Y. Review of the application of social network analysis (SNA) in construction project management research. Int. J. Proj. Manag. 2016, 34, 1214-1225. [CrossRef]

29. Gloor, P.A.; Fronzetti Colladon, A.; Grippa, F.; Giacomelli, G. Forecasting managerial turnover through e-mail based social network analysis. Comput. Human Behav. 2017, 71, 343-352. [CrossRef]

30. Caniato, M.; Vaccari, M.; Visvanathan, C.; Zurbrügg, C. Using social network and stakeholder analysis to help evaluate infectious waste management: A step towards a holistic assessment. Waste Manag. 2014, 34, 938-951. [CrossRef] [PubMed]

31. Mitchell, J.C. The concept and use of social networks. In Social Networks in Urban Situations; Institute for Social Research, University of Zambia: Lusaka, Zambia, 1969; 50p.

32. Chinowsky, P.; Diekmann, J.; Galotti, V. Social network model of construction. J. Constr. Eng. Manag. 2008, 134, 804-812. [CrossRef]

33. Wasserman, S.F.K. Social Network Analysis: Methods and Applications; Cambridge University Press: Cambridge, UK, 1994.

34. Mok, K.Y.; Shen, G.Q.; Yang, J. Stakeholder management studies in mega construction projects: A review and future directions. Int. J. Proj. Manag. 2015, 33, 446-457. [CrossRef]

35. Brinkmann. Interview; Springer: New York, NY, USA, 2014. 
36. Li, C.Z.; Hong, J.; Xue, F.; Shen, G.Q.; Xu, X.; Mok, M.K. Schedule risks in prefabrication housing production in Hong Kong: A social network analysis. J. Clean. Prod. 2016, 134, 482-494. [CrossRef]

37. Freeman, R.E. Strategic Management: A Stakeholder Approach; Cambridge University Press: Cambridge, UK, 2010.

38. Qin, H.; Gao, J.; Kluger, R.; Wu, Y.J. Effects of perception on public bike-and-ride: A survey under complex, multifactor mode-choice scenarios. Transp. Res. Part Traffic Psychol. Behav. 2018, 54, 264-275. [CrossRef]

39. Zhao, J.; Deng, W.; Song, Y. Ridership and effectiveness of bikesharing: The effects of urban features and system characteristics on daily use and turnover rate of public bikes in China. Transp. Policy 2014, 35, 253-264. [CrossRef]

40. Audikana, A.; Ravalet, E.; Baranger, V.; Kaufmann, V. Implementing bikesharing systems in small cities: Evidence from the Swiss experience. Transp. Policy 2017, 55, 18-28. [CrossRef]

41. Kaplan, S.; Manca, F.; Nielsen, T.A.S.; Prato, C.G. Intentions to use bike-sharing for holiday cycling: An application of the Theory of Planned Behavior. Tour. Manag. 2015, 47, 34-46. [CrossRef]

42. Wilson, O.; Vairo, N.; Bopp, M.; Sims, D.; Dutt, K.; Pinkos, B. Best practices for promoting cycling amongst university students and employees. J. Transp. Heal. 2018, 1. [CrossRef]

43. Paundra, J.; Rook, L.; van Dalen, J.; Ketter, W. Preferences for car sharing services: Effects of instrumental attributes and psychological ownership. J. Environ. Psychol. 2017, 53, 121-130. [CrossRef]

44. Shi, J.; Si, H.; Wu, G. Using behavior willingness of urban transportation sharing products from the perspective of sustainable development. China Popul. Resour. Environ. 2018, 28, 63-72.

45. Zhu, D. Urban Sharing Travel in Post-Car Era: A Discussion Based on Circular Economy. Urban Transp. China 2017, 15, 12-19.

46. She, Y.; Shen, L.; Jiao, L.; Zuo, J.; Tam, V.W.Y.; Yan, H. Constraints to achieve infrastructure sustainability for mountainous townships in China. Habitat Int. 2018, 73, 65-78. [CrossRef]

47. Jia, J.; He, X.J.Y. Statistics; China Renmin University Press: Beijing, China, 2012.

48. Yang, R.J.; Zou, P.X.W. Stakeholder-associated risks and their interactions in complex green building projects: A social network model. Build. Environ. 2014, 73, 208-222. [CrossRef]

49. Yang, R.J.; Zou, P.X.W.; Wang, J. Modelling stakeholder-associated risk networks in green building projects. Int. J. Proj. Manag. 2016, 34, 66-81. [CrossRef]

50. Gould, R.V.; Fernandez, R.M. Structures of mediation: A formal approach to brokerage in transaction networks. Sociol. Methodol. 1989, 19, 89-126. [CrossRef]

51. Li, D. Bike-sharing, how to bid farewell to "rubbish mountain"? Resour. Recycl. 2017, 34-37.

52. Yang, S. Waste bike-sharing facing recycling problems. Work. Dly. China, 13 July 2017; p. 4.

53. Karki, T.K.; Tao, L. How accessible and convenient are the public bicycle sharing programs in China? Experiences from Suzhou city. Habitat Int. 2016, 53, 188-194. [CrossRef]

54. Wang, H.; Xiong, W.; Wu, G.; Zhu, D. Public-private partnership in Public Administration discipline: A literature review. Public Manag. Rev. 2018, 20, 293-316. [CrossRef]

55. Stark, J. Product Lifecycle Management (Volume 1); Springer: Cham, Switzerland, 2015; ISBN 9783540443735.

56. Lodhia, S.; Martin, N.; Rice, J. Extended Producer Responsibility for waste televisions and computers: A regulatory evaluation of the Australian experience. J. Clean. Prod. 2017, 164, 927-938. [CrossRef]

(C) 2018 by the authors. Licensee MDPI, Basel, Switzerland. This article is an open access article distributed under the terms and conditions of the Creative Commons Attribution (CC BY) license (http:/ / creativecommons.org/licenses/by/4.0/). 